it would do him no harm, for the parasite is not directly transmissible from these animals to man. If, however. the hydatid worm is fed to a dog, each separate head of the cyst, and there may be thousands in a single cyst, develops into a tape-worm. It is probably the smallest tape-worm known, having very few segments, and only the last segment is gravid with eggs. The dog scatters the eggs of this tape-worm broadcast and the domesticated animals become infected with it. Manizind may also become infected with this parasite by a too close intimacy with dogs. In Iceland where men and dogs live during the long months of winter in the same huts and without any idea of sanitary precautions, it is said that one person out of 43 is affected with the echinococcus disease. In some parts of Germany the disease is also very froquent. Ostertag gives a table from which it appears that at Rostock out of 1026 post-mortems on man 25 cases were found, or 2.43 per cent.; at Breslau out of 1360 post-mortems there were 20 cases, or 1.47 per cent.; at Berlin out of 4770 post-mortems there were 33 cases or 0.76 per cent. It is also alleged to be common in Siberia, India and Australia. The disease can only be controlled by careful meat inspection and the destruction of all hydatids that are found. Unfortunately the local slaughter-houses of this country are not looked after so closely as they should be. It is often an easy matter for dogs to gain access to such premises and to become infected with this parasite and thus propagate the infection. To prevent this and other discases there should be expert supervision over all slaughter-houses. Places for slaughtering should be reduced in number so that all the butchers of a town or village would slaughter at the same place and the premises where slaughtering is done should be under the surveillance of the local board of health. Offal feeding should be done away with in order to prevent the propagation of this class of parasites, and under no circumstances should a dog ever be allowed on the premises.

I trust this brief and somewhat superficial review of the subject of meat inspection, and the exhibition of specimens, may serve to increase the interest of physicians in this branch of sanitary work. It is only through the examination of the pathological specimens actually found by the meat inspectors that we are able to appreciate the importance of having experienced and eduated men on guard to withdraw carcasses so affected from the meat-supply of the country. The great mass of our citizens have no conception either of the diseases found among animals at the abattoirs, or of the enormous amount of work which our government is doing to protect them from diseased animal products.

No public work, however, can long be sustained or earried to the highest degree of efficiency unless the people of the country understand its objects and value and become interested in it. This being true as a general proposition, we can hardly expect the mear-inspection service, interfering as it must more or less with some of the wealthiest and most powerful industrial organizations in the world, to be conducted with vigor and a rigid adherence to correct principles, unless there is a popular appreciation of the value of the work to every consumer of meats. This service must appeal first of all to the physician, who, being familiar with pathological appearances, can by inspecting these specimens judge of their seriousness and their influence on the public heaith.

NoN-ALCOHOLIC INSANITY is decreasing in Scotland, while alcoholic insanity is increasing, according to the past year's records of the Edinburgh Asylum for the Insane.
THE TREATMENT OF PROLAPSE OF THE RECTUM.*

\author{
JOSEPH M. MATHEWS, M.D., LL.D. \\ LOUISVILLE. $\mathrm{KY}$.
}

There is perhaps no pathologic condition which affects the rectum, that gives so much concern to the surgeon, as a serious prolapse. It is not to be understood that reference is had to the prolapse that occurs in infancy or to the milder forms met with in adult life. I have yet to see a prolapse of the rectum, incident to young life, that has not readily yielded to the following simple plan of treatment. viz.: Administration of a gentle purgative and, when it acts, the protruded gut is washed with cold water and returned. Then the physician in attendance straps together the two buttocks, bringing them in close apposition by means of adhesive plaster. This is allowed to remain on for four or five days, and the little patient is kept in bed and permitted to have only liquid nourishment. At the end of this time the adhesive strips are removed and the bowels allowed to move in response to a dose of castor-oil and an enema of cold water. The child should be allowed to have its action from the bowels while lying on the back. The adhesive plaster strips are then reapplied and the child put to bed for another five days-the purgative is again given, when it will be observed that the gut will no longer protrude if the proper attention is given the position of the patient during the action of defecation, which should be either in the erect one or reclining upon its back. The application of fuming nitric acid or other caustics should be deprecated in all such cases.

\section{LINEAR CAUTERIZATION.}

Linear cauterization is recommended by some, notably Van Buren, in his most excellent work on "Diseases of the Rectum." It was advised by him to use the actual cautery-iron in most all cases of prolapse of the rectum. The truth is that the remedy is too severe to use in simple cases, and is of no benefit in the graver ones. Its application would often result in hemorrhage if the iron is applied sufficiently hot to cause a slough, and unless a slough does occur, no benefit is derived from this mode of treatment.

\section{AMIPUTATION.}

The former custom of cutting out an elliptical piece of the gut and drawing it together by sutures is so unsatisfactory in its results that it will not be discussed here. Amputation of the "prolapse" is, however, an operation advocated by a good many and should receive carcful consideration. We must remember that it is often a difficult matter to tell just what kind of a prolapse is being dealt with. A prolapse of mucous membrane alone can be amputated and tied off, just as hemorrhoids are treated. But to cut off a more serious prolapse, means the opening of or the wounding of the peritoneum with perhaps dangerous complications, not to speak of subsequent contraction as the result of the amputation. This phase of the subject has been carefuly considered by modern operators, and I beg to call attention to a recent report of such a case by Dr. George Ryerson Fowler ${ }^{1}$ of New York. He says:

In a case of large rectal prolapse recently under my care at the Brooklyn Hospital, the following method of carrying out the procedure of amputation of the prolapse proved to be comparatively easy of performance, and was followed by a most excellent result. The patient was a male in whom the

* Read before the Chicago Medical Society by invitation.

1. Med. News, Dec. 8,1900 . 
mass protruded about five inches, and had been in existence for five years.

Analgesia was effected by means of spinal cocainization. The patient was placed in the combined lithotomy and Trendelenburg position. Being fully conscious, he was able to bear down forcibly and extrude the prolapse fully, thus doing away with the necessity for traction upon the latter. A row of fenestrated or ring-headed forceps (common artery clamps will answer, but do not hold so well) was placed just in front of the junction of the mucous membrane with the skin of the anus in such a manner as to pinch up a circular fold of the mucous membrane of the outer cylinder for the entire circumference of the gut. About half an inch in front of this again an incision was made, likewise for the entire circumference of the outer cylinder of the gut, this incision exten ling through the mucous membrane only. Its proximal edge was disseeted back for a half-inch. 'Two clamps were now placed, one upon either side, at the point of the prolapse, or the place where the outer cylinder of the gut returns to form the inner cylin der. With the mass thus steadied and the rwo cylinders identified, the index finger of the left hand was passed up the inner cylinder, and with this as a guide the cylinder incision already made in the circumference of the outer cylinder was deepened to the extent of a half inch so as to include the remainder of the thickness of the Iatter and the inner cylinder

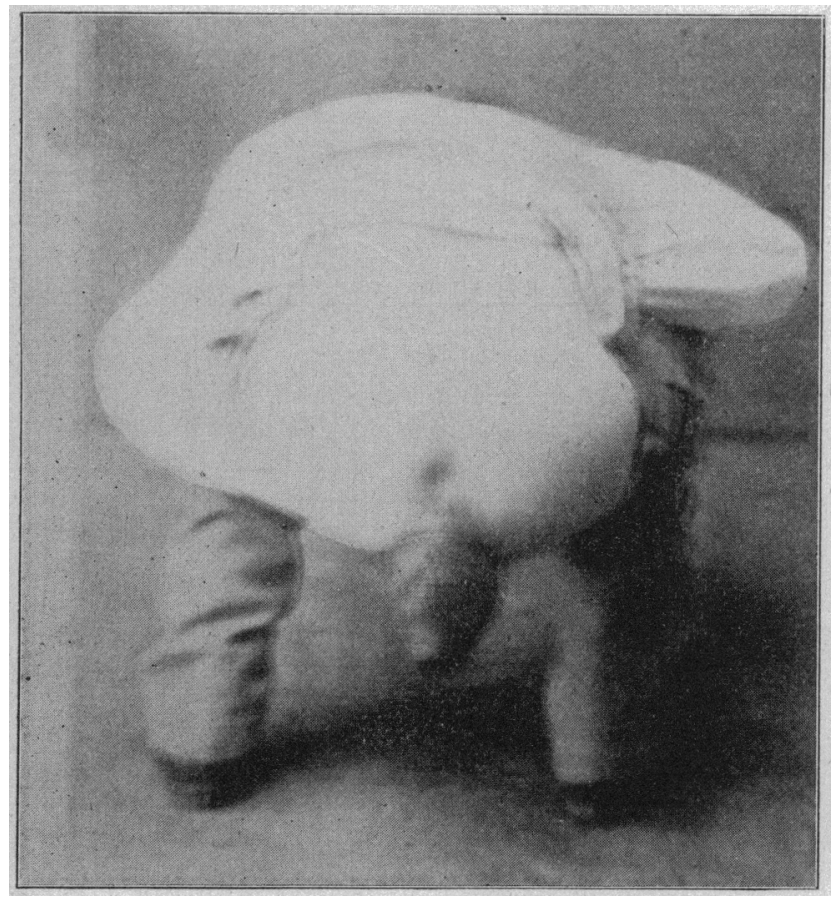

through its entire thickness to the finger inside the latter. A suture of catgut was now placed so as to include the entire thickness of the two cylinders where the half-inch opening was made, with the exception of the turned-back inuceus membrane cuff at the anal mucocutan:ous unigin grasped at first by the fenestrated forceps. This step of the operation was repeated until the entire circumference of the cylinders was transversed, save that each subsequent suture was first applied and the incision extended afterward. Care was taken that each extension of the incision was carried no farther than the area previously secured by the suture. Throughout this por tion of the operation a stream of warm borosalicylic (Thiersch) solution was kept playing upon the parts. When the posterior portion of the circumference was reached the mesenteric attachment of the gut was encountered. This was treated precisely as the interior portion, no difficulty being encountered in securing the ressels of the mesentery in the suture. As the last suture was applied the final cut was made in front of it, completing the amputation of the prolapse. The dissected-back mucous membrane at the mucocutaneous margin, which up to this time had been held in the grasp of the forceps first applied, was now replaced and sutured in position over the first rows of sutures. Alcolıol-boiled catgut was used as suture material throughout the entire operation. The patient suffered not the slightest pain during the entire operation, nor inconvenience either then or thereafter from the spinal cocainization, save slight nausea and mild headache.
An opium suppository was placed high up in the bowel, and the parts replaced. A light tampon of zinc oxid gauze was placed in position for forty-eight hours, after which it was removed and a castor-oil eathartic given, followed in three hours by a sweet-oil enema.

The advantage of this method consists: 1 , in the use of the combined lithotomy and Trendelenburg position, in order to prevent the descent of the small intestines during the operation, and thus providing against injury to these during the suturing; 2, in turning back a cuff at the mucocutaneous margin for the purpose of preserving the normal conditions at the rectal outlet, and at the same time permitting the removal of all the relaxed and overstretched mucous and submucous structures at this point. This cuff also provides a covering for the sutured edges of the stump of the prolapse and diminishes opportunities for subsequent infection; 3 , in the step-by-step application of, first, a suture and then an extension of the incision through both evlinders to correspond with the sutured area, in this manner avoiding exposure of the peritoneal cavity to infection.

It is not elaimed that this operation possesses all of these advantages exclusively. Several of them are features of one or another operation. I do not remember, however, to have seen them all combined in one procedure before.

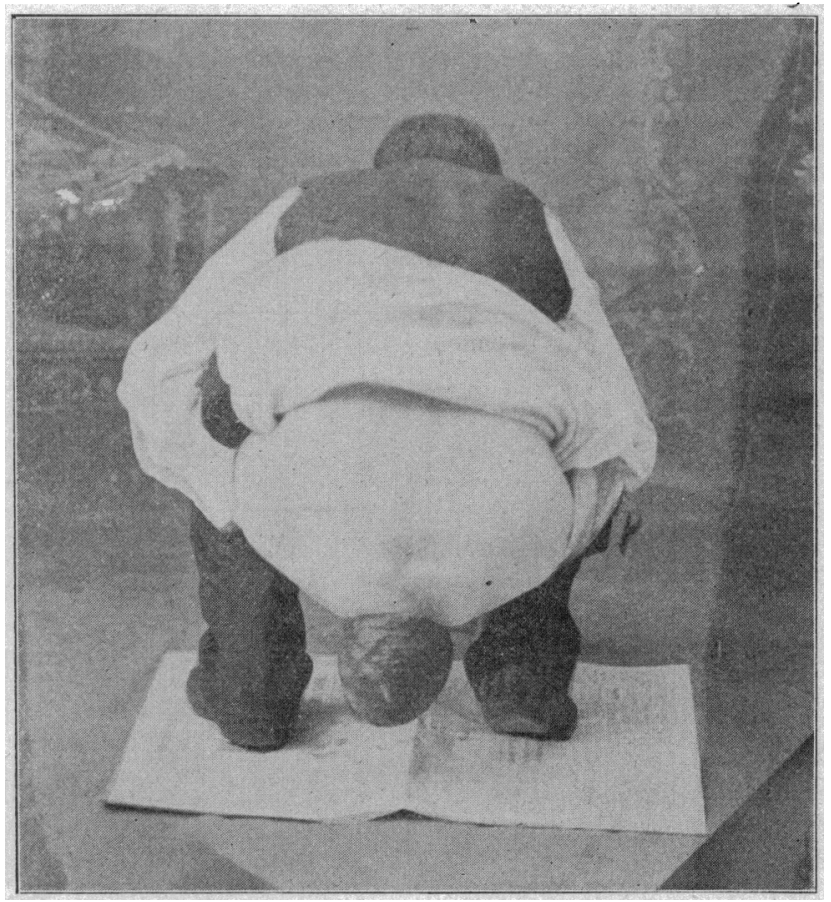

Whereas Dr. Fowler does not claim that the operation is an original one in all its details, it does possess unique features and was attended by a brilliant result. However, there are some formidable objections that could be urged against it. but the scope of this paper will not permit. I have for many years been interested in the study of this affection, and have tried many if not all the plans of treatment for its cure, and must confess to disappointment in them all as a rule. The matter of curing a formidable prolapse of the rectum in the adult is no simple matter, and simple means will not avail. It was after several complete failures that I determined to try an original plan-at least so far as it was known to me-viz., to open the abdomen and anchor the colon or flexure for the cure of a longstanding prolapse of the rectum. Before reporting this case I desire to mention one reported by Dr. Chas. P. Noble, ${ }^{2}$ of Philadelphia, who says :

Marked prolapse and inversion of the rectun in adults is a condition which is well known for its intractable nature and for the difficulty of effecting a cure. It is not my purpose

2. Am. Gyn. and Obstet. Jowt.. I December, 1900. 
to discuss the etiology of the condition nor the treatment of the recent and more simple cases, which can often be cured by the removal of the cause, and careful attention to the regula tion of the bowel movements. I desire to advocate a simple method of operation which promises well in the treatment of intractable cases, and to report two cases in which this opera tion has been performed. The operation which I would propose is to open the peritoneal cavity by an incision made through the left rectus muscle slightly below the promontory of the sacrum, to search for the sigmoid or for the rectum and to make traction upon it until it is inverted and until "the slack" has been taken up. The point at which the lower portion of the rectum will come in contact with the abdominal wall on slight tension should be determined, and this point attached to the abdominal wall by three or more fine silk sutures. The sutures should be passed so as to include a portion of the rectus muscle, and should pass under the anterior longitudinal band of the rectum. In this way the bowel can be firmly attached to the abdominal wall with the least danger of penetrating its lumen and with the greatest prospect of permanent attachment. The abdominal wall should then be closed by the tier method.

The history of the two cases is as follows:

Mrs. I., aged 35, primipara, consulted me Marsh 21, 1899. She complained of backache and a feeling of discomfort about the rectum, which she attributed to piles. She stated that she had lad piles for about five years and that these came down and gave her a great deal of annoyance. The general examination threw no light upon the local trouble. Her health was otherwise good. Her bowels were obstinately con. stipated. Upon examination the supposed piles proved to be inverted rectum. Because of the unsatisfactory results thich are usually obtained from the various direct operations upon the protruded bowel, I determined to perform a proctorrhaphy, which was done two days later. She made a prompt recovery, and was discharged from the hospital March 25. Her physician has told me within a month that the operation has effected a permanent cure. She is perfectly well, with zhe exception that there is some tendency to constipation, for which it is necessary to administer a laxative.

Miss D., aged 19, consulted me March 13, 1900, complaining of a sense of weight or bearing down about the rectum and intense buckache. During each bowel movement there is :n inversion of the rectum. For some time she has iad but little control over her sphincter muscle. The present trouble began three years ago, after an attack of constipation, for which she took a powerful cathartic. Her bowels are constipated, but otherwise there is nothing in the history bearing upon the local trouble. Upon examination the sphincter was found in a paretic condition. In the Sims' position or in the kneeelbow position it dilated under atmospheric pressure, so that the rectum filled with air. Examination with the proctoscope showed a relaxed rectum, which was otherwise normal. On April 16 proctorrhaphy was performed. The patient made a good recovery and was discharged about five weeks after the operation. She consulted me in November, seven months after the operation, and reported that she had no troub'e with her rectum until within a few weeks, since which time there has been some tendency to eversion of the bowel at stool. She is still constipated and has not taken her laxatives regularly. Upon examination, the anus was found in normal condition, the bowel in situ and, so far as an examination could show, tne operation was entirely successful. As against this we have the statement of the patient that there is a tendency to recurrence of the old trouble. It is my judgment that reasonable care in the administration of laxatives and the use of enemata, so as to avoid constipation and straining, will be sufficient to effect a permanent cure.

When I operated on the first ease, March 23, 1899, I was under the impression that the operation was original with $m y$ self. I have since learned that it has been done by Dr. W. Jos. Hearn, of Philadelphia, in one ease with good resuit. Probably the first surgeon to perform this operation was McLeod, of Calcutta (B. K. McLeod, F.R.C.S.E.: "A New Operation for Prolapse of the Rectum," Lancet, vol. ii, p. 117, 1890). The technique which he employed, however, would not be likely to appeal to most surgeons. J'e introduced his hand into the rectum, reduced the inversion, put the rectum on the stretch from below upward, and pressed the recrum against the abdominal wall, endeavoring to peess the small bowels to one side so that the rectal wall would come in contact with the abdominal wall. Two acu-pressure pins were introduced through the abdominal wall and through the rectum, penetrating its lumen, so as to fasten the rectum to the abdominal wall. These pins were separated by an interval of three inches, and they were so introdued that the rectum was made to take the course of running from below upward and from within outward. Having fixed the rectum to the abdominal wall, an incision was made between the pins down to, but not through, the parietal peritoneum. The hand was again introduced into the bowel as a guide, and tine sutures were introduced through the abdominal wall, and through the wall of the bowel, avoiding its mucous membrane, and then out through the opposite side of the wound. In this way the rectal wall was attached to the abdominal wall. The acu-pressure pins were removed after twenty-four hours. The patient made a fairly good recovery, the wound healing by first intention. The result was a cure.

It will be noticed that the cases reported by Dr. Noble were not types of prolapse even of the second degree, and in no way compare with the report of my case in severity of symptoms or extent of the affection.

On April 1\%, 1899, Mr. G. N. McL. was referred for operation, by his family physician. He gave the following statement of his case by request.

In February, 1865, while in camp and on line of duty at Fort Fisher, N. C., and on the marches through the state, I contracted a chronic diarrhea, which, with short intermissions, continued for many years, often confining me to bed. The prolapse commenced shortly after taking diarrhea and I was never entirely well of it afterward, but continued to get worse until, in 1875, when I quit all kinds of manual labor. From 1875 to 1885 I grew much worse, being much weaker and miserable. Diarrhea was bad by spells. From 1885 to 1895 diarrhea almost ceased, but the prolapse was much worse. From 1895 to 1899 , diarrhea was less, prolapse much worse, though I was not confined to bed, but required a nurse most of the time. I was operated on April 17, 1899 .

On examination it was found that the patient was suffering from an immense prolapse, in size about the measurement in circumference of a No. 7 Derby hat. (See photos.) It contained all the coats of the rectum, peritoneum, and in addition the bladder. In determining the method of operation, the fact of the presence of the bladder dissipated any idea of amputating the mass. When I made a statement of the formidable operation that might be required to effect a cure, he replied that life was a burden to him and that he would take any kind of a risk. After thorough preparation, he was placed under chloroform, and the bowel made to protrude to its fullest extent in order to examine it more fully. The thickness of its walls was truly amazing, and had the effect of making me doubt whether so heavy a mass could ever be held in place. An incision was made in the left inguinal region, extending upward about six inches. The hand of a competent assistant reduced the mass and was pushed with it up the rectum until the fingers could be felt in the sigmoid flexure by the operator. This procedure was found to be of wonderful assistance during the operation. The gut was now drawn taut and anchored to the abdominal muscular wall by a running suture of chromotized catgut for fully three inches. Simple anchoring by the interrupted suture would not have availed anything. I am sure, in this case. The abdominal wound was closed. the patient put to bed, position on the back, with the foot of the bed elevated. He was kept in this position for two weeks, with watchful care. The bowels were moved on the fifth day by an aperient assisted by an enema. This was repeated in another five days. At the end of two weeks he was allowed to change position and recline on his side. The rectum was irrigated with a simple antiseptic solution every day. In the act of clefecation, he was directed to always use the bed-pan during this time. At the expiration of a month his bowels moved on the commode without protrusion. I should state that after all the mass was pushed back, there was found to still protrude, mucous membrane about the 
size of a case of well-formed internal hemorrhoids. This proved fortunate, for by its simple ligation, a strictured condition resulted which was of great service at the anal orifice. It can be quite understood that the sphincter muscles were so distended by this great mass as to be nearly unrecognizable and without power of control.

The question naturally suggested was whether the muscle would ever regain its power and. if so, to what extent? Also, would this wonderfully thickened gut ever be thinned to assume or approximate the normal. I am glad to report that both conditions were eventually brought about. About one year after the operation was done I examined him, in company with Dr. Geo. J. Cook of Indianapolis, and found good contractile power in the sphincter, and the gut thinned to nearly a normal condition. On June 25 , about two months after the operation, the patient wrote: "I have been using the water-closet, and there is no indication of the bowel coming down." He has continued to improve ever since and gained much in flesh. This case has never been reported.

I conclude: 1 . That in all cases of prolapse of the rectum of the second or third degree, colopexia is to be preferred to all other procedures. 2. That it is the least dangerous of any surgical procedure advised for prolapse. 3. That the uninterrupted suture should be used in preference to the interrupted, especially in cases when the mass is large or the walls of the gut much thickened.

Mr Carlyon, ${ }^{3}$ of London, says that he has only been able to find three cases of colopexia operations. $\mathrm{He}$ does not intimate for what degree of prolapse these were done. The operation referred to by me was done in April, 1899, and at that time I had never heard of its being done. Though, therefore, not original with me, I thought at the time that it was. No case that I have yet heard of compares in magnitude to this one, and I trust that by now reporting it, two years after the operation, the said report may prove of some benefit to those desiring to operate for so formidable a malady. In 1889, Jaennel fixed the colon to an artificial anus wound in the iliac region. Bryant found records of twenty-nine cases done by this method. In my opinion this procedure is not only unnecessary, but unjustifiable. Dr. Bovée, of Washington, reports an interesting case of colopexia done on a woman during an abdominal section after the ovaries and appendages had been removed.

In reporting this case I desire to thank my friend. Dr. Ap Morgan Vance for valuable assistance and suggestions.

\section{SANITARY CONDITIONS OF PEKING.}

JOHN INGIIS, A.M., M.D.

MEMBER OF THE AMERICAN MEDICAL ASSOCIATION. PEKING, CHINA.

The Chinese army has been driven from Peking, the Empress and her co-conspirators have fled, the order is cut for the punishment of the most guilty and the sacred city, we are told, is well patrolled by the foreign soldiers. All true, but those who have lived in Peking know that within a year, unless certain measures are taken, officers and men will discover a deadlier foe than the Empress Dowager's imperial troops, and the death-roll will be longer than it was after the taking of Fort Taku and Tien-Tsin.

Population.-The population of Peking is unknown, perhaps not being so great now as before the recent uprising, but still close to the one million mark. Some writers have greatly overestimated the number of inhabitants in this famous old city. Peking lies near the fortieth degree north latitude,

3. The Irancet. December 1899 . ninety miles from the sea and one hundred and twenty feet above sea-level. It is surrounded to the north and west with mountainous hills, to the south lies the great piain of central China; the latter is sandy but well watered.

Climate.-The climate is similar to that of New York, but much more trying, especially during the spring and summer. From November until March the weather is cold, but March is windy there as elsewhere, and sand storms blow over the city; these are not only disagreeable, but dangerous. In April the temperature rises and in May reaches 90 to $95 \mathrm{de}$ grees F. During May and June thunderstorms and rains are to be expected, and these are frequently the forerunners of an almost continual downpour which lasts from July to the

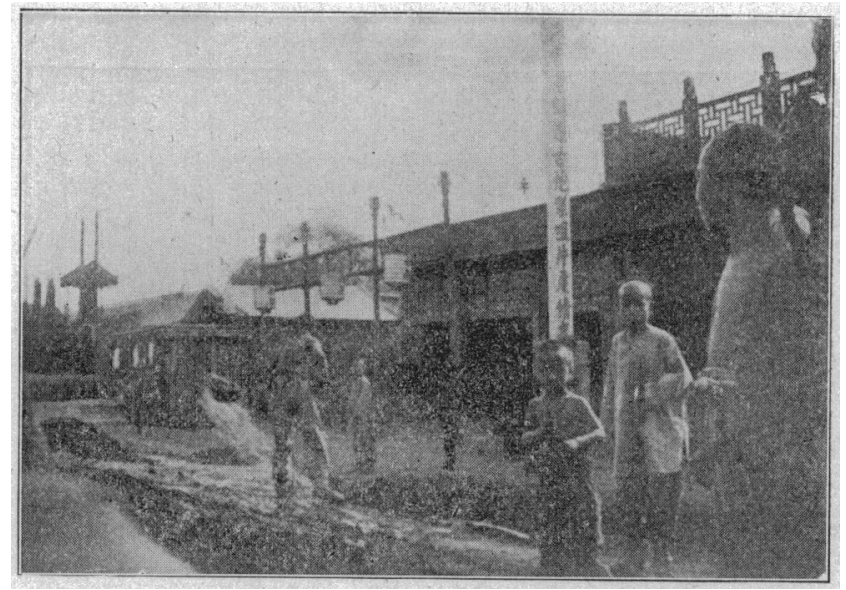

Street Sprinkler

early part of September. The annual rainfall ${ }^{1}$ varies from 46 to 76 inches, but after the rainy season is over, with the exception of some very dusty days, the fall weather is delightful.

Water Supply.-A study of the sanitary conditions of Peking reveals much of a threatening nature and, if it teaches nothing new, throws indisputable proof in favor of cur present ideas concerning the causation of disease. The eity is without water-works, and has no sewerage system worthy of the name. The Chinaman believes in open sewers, claiming that it is better to leave the foul gases free than to pen them beneath the ground. But whether this is based on some scien.

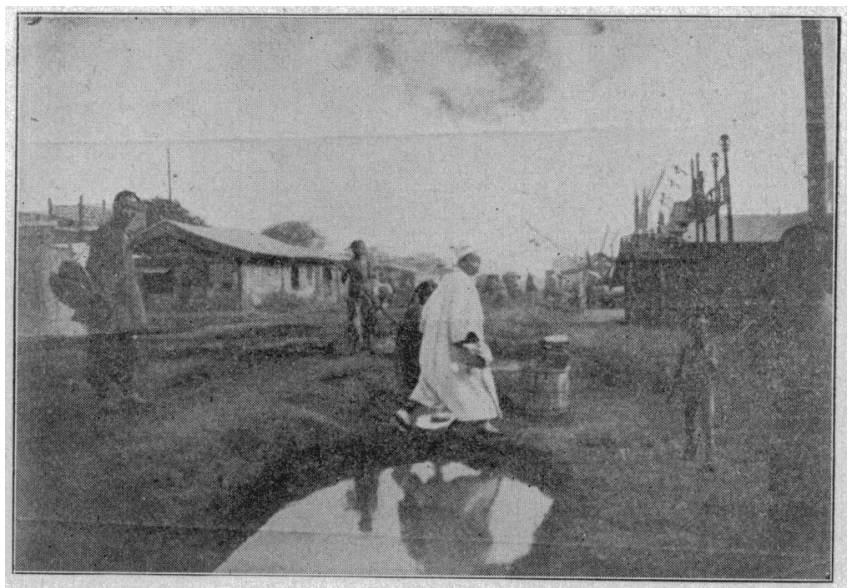

A Cesspool on one of the Main Streets.

tific theory not yet explained, or ignorance of refuse disposal, I can not say, but am inclined to attribute it to ignorance. The water-supply is from wells dug along the sides of the streets; a heavy stone covers the well's mouth and the water is drawn in wooden buckets by rope and pulley; the presence of an open sewer ten feet away, or even running by the mouth of the well, in no way seems to militate against the site on which to sink a well. How of ten these wells are cleaned out it is impossible to learn, but it may be safely affirmed that they are cleaned only when enough dirt gathers in the bottom to interfere with the filling of the well. The water itself is

1. There is no oflcial record. This is the average for a number of years past. taken by different observers. 